\title{
Trial to Determine Durability and Serviceability for Swine Farm in Thailand
}

\author{
L Lapcharatsangroj and Chalida U-tapao \\ Department of civil engineering, King Mongkut's Institute of Technology Ladkrabang. 1 Soi Chalong Krung 1, Chalong Krung Road, \\ Ladkrabang, Ladkrabang, Bangkok, Thailand 10520
}

\begin{abstract}
In agricultural construction, the most frequently used construction material is concrete. In particular swine farm, traditional concrete flooring system in the business is conventional concrete. However, the conventional concrete floor has several key issues on its surface. They are easily to be spalled and cracked, pig scour, rough areas, and low wear resistance of acid from animal feed. This research involves study in the ratio between Portland cement and supplementary materials (fly ash and silica fume) that is the most resistant to abrasion. Concrete samples were cured in water for 28 days, then submersed in lactic acid solution at $30{ }^{\circ} \mathrm{C}(\mathrm{pH} 2-3)$. After exposure to the acid solution, every 7, 14, 28, and 56 days, the samples will be test for attrition on the face of concrete in accordance with ASTM C944 to simulate the acceleration reaction refer to animal behaviour and corrosion from acid of feed. From experiment, it was found that increasing the volume of fly ash and silica fume can increase concrete resistance to corrosion due to acid derived from feed.
\end{abstract}

\section{Introduction}

The construction of Thai swine farms is generally made of concrete. It is crucial that the swine farm floor must be smooth but non-slippery. Normally, the floor is casted by farmers or contractors who usually build it with conventional concrete or just use reinforcement in the solid floor. Concrete is one of the most frequent used as building material. It is not only for general construction but also for a specific purpose like the agricultural construction, where the floor is aggressively subjected to chemical erosion and physical force such as cleaning, acid from animal feed and animal behaviours. [1]

This document purpose is to enable an assessment of a swine building's construction and key factor of the concrete surface's strength in the building and structure is agricultural environment. [2] The surface may be exposed to aggressive composition like chemical and physical environment. Hence, concrete material for swine building floor should be high quality material that resistible against the chemical and physical attacks. [3] The information following will present a reviewing of recent performed research in durability of building materials and components in agricultural environment. Leading to the development of 'special concrete for farm floor' with a concept of increasing in resistance in erosion due to lactic acid derived from animal feed; corn, wheat, manioc, so forth. Moreover, the concrete mass is also increased the hardiness to be durable from animal behaviour such as scratching that is caused of craggy and coming apart. [4]

In fact, there are many factors that could cause damages on swine farm floors. The various sorts of cleaning equipment and methods make it more difficult to precisely and concisely identify the actual cause of the floor corrosion. It is also more complicated owing to the environmental dissimilarity in each area (urban, rural, and coastal). [1] Consequently, concrete becomes common used in every farm due to its ability that can be in any forms, durability, strength and suitability to environmental practices. Mostly, concrete is made from lime-based concrete like Portland cement concrete or other hydraulic cements. [5] It requires other processing and value-added facilities like composting and anaerobic digestion facilities as integral parts in the operations. The compressive strength depends on the proportions of compound ingredients, i.e. water-cement ratio, and the cement aggregate ratio. Furthermore, superplasticizers was used in the mixed design. [6] Superplasticizers help in removal of $15 \%$ or adding water from the mixed design or increasing concrete workability (slump).

\section{Related literature}

Nowadays, the demand in pork products is increasing. It causes not only the growth in numbers of swine but also the numbers of slaughter weight. In Thailand, swine farm mostly consists of concrete.[7] Eighty percent of concrete floors in swine farms were cast by farmers or contractors, usually with conventional concrete. These floors are directly subject to chemical attack by cleaners, feed acids and animal behaviours (see Figure 1 and Figure 2). From Figure 3 and Table 1, livestock is one of the main agricultural activities where mainly in Central region's 
provinces of Thailand such as Nakhornpathom, Ratchaburi, and Chachoengsao.[7] The livestock and poultry farms could be divided into two types: commercial farms (big operators) and non-commercial farms (backyard farms). This document enables an assessment of the opportunities and issues involved with constructing and operating a pig finishing building.

\subsection{Methods to protect concrete structures}

\subsection{Concept design}

Concrete samples with the materials and mix designs in Table 2 were prepared for compressive strength and abrasion resistance test and three methodologies that are used to define the results.

\subsection{Testing concrete}

\subsubsection{Compressive Strength}

Most important property of hardened concrete. Generally considered in the design of concrete mixtures. Compressive strength is affected by many factors (environmental, curing condition). Therefore, the actual strength of concrete will not be the same as the strength of specimen. Dimensions of the concrete specimens usually have the following sizes: cube specimens $15 \times 15$ $\mathrm{cm}$. Empty moulds are filled with fresh concrete using a standard procedure and test compressive strength.

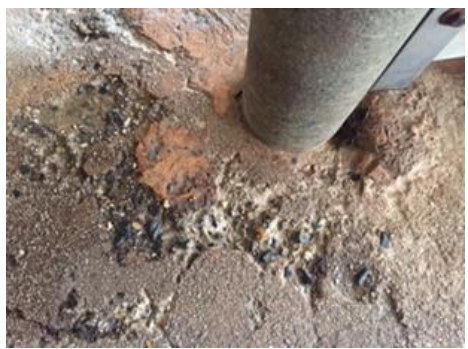

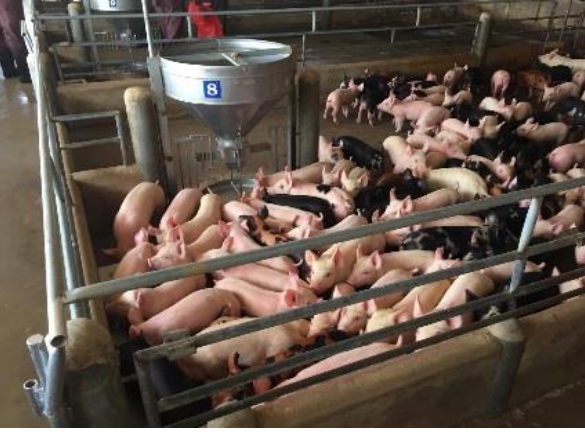

Figure 2. Swine Farm

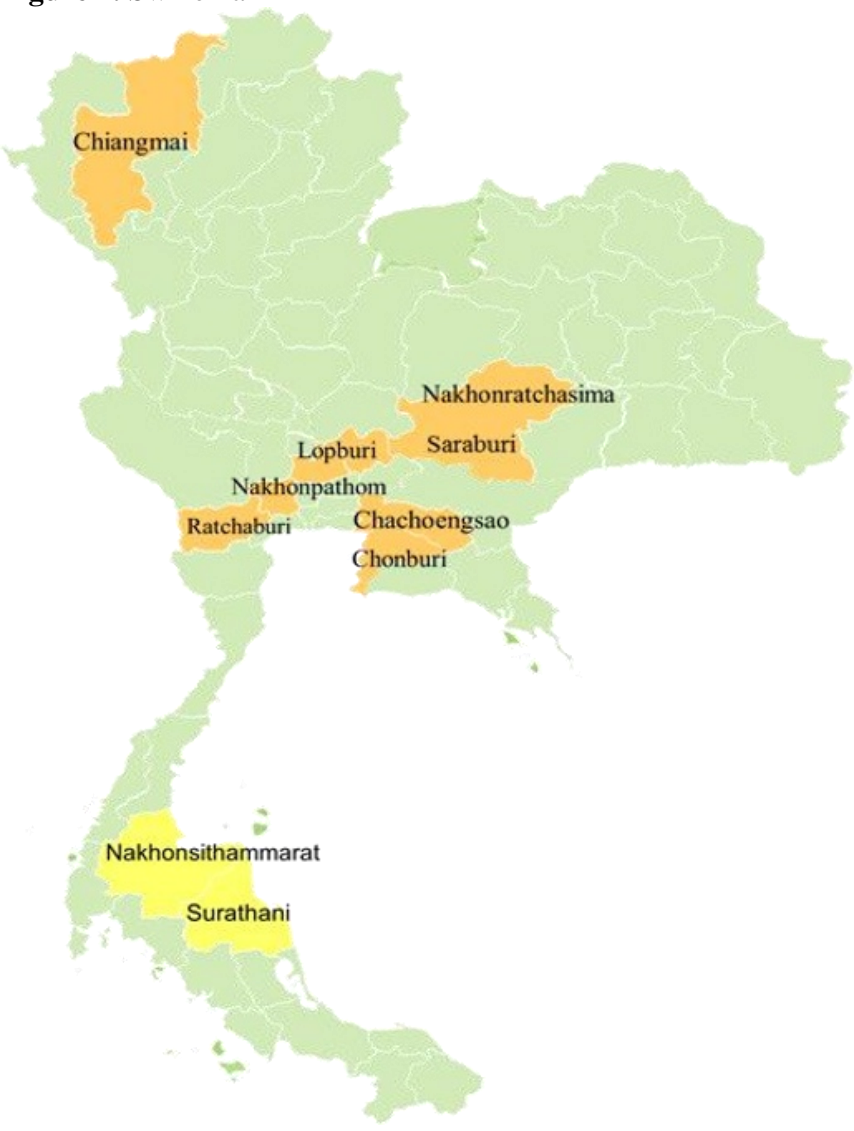

Figure 3. Map of Thailand

Figure 1. Spalling

Table 1. Top 10 Province of Pig Farm

\begin{tabular}{lcccr}
\hline \multicolumn{1}{c}{ Province } & Region & Number of Pig (Heads) & $\begin{array}{c}\text { Area } \\
\text { (sq.m.) }\end{array}$ & \% \\
\cline { 2 - 5 } Ratchaburi & Central & $1,468,839$ & $19,094,907$ & 19 \\
Nakhonpathom & Central & 914,718 & $11,891,338$ & 12 \\
Chachoengsao & Central & 456,419 & $5,933,451$ & 6 \\
Chonburi & Central & 310,758 & $4,039,854$ & 4 \\
Chiangmai & North & 297,217 & $3,863,821$ & 4 \\
Nakhonratchasima & North-east & 246,482 & $3,204,262$ & 3 \\
Saraburi & Central & 205,330 & $2,669,286$ & 3 \\
Nakhonsithammarat & South & $1,468,839$ & $19,094,907$ & 2 \\
Surathani & South & 914,718 & $11,891,338$ & 2 \\
Lopburi & Central & 139,402 & $1,812,222$ & 2
\end{tabular}


Table 2. Description of mix design

\section{Detail/ Mix design}

Cement type (ASTM C150)

Cement $\left(\mathrm{kg} / \mathrm{m}^{3}\right.$ of concrete)

Water $\left(\mathrm{kg} / \mathrm{m}^{3}\right.$ of concrete)

w/c ratio

Fine aggregate

$\left(\mathrm{kg} / \mathrm{m}^{3}\right.$ of concrete)

Coarse aggregate

$\left(\mathrm{kg} / \mathrm{m}^{3}\right.$ of concrete $)$

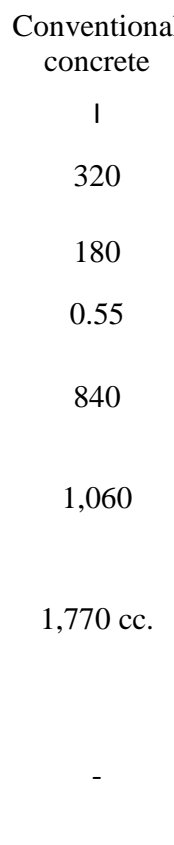

\subsubsection{Abrasion Resistance Test (ASTM C944)}

This test could cover a process of determining the resistance of either concrete to mortar to the abrasion. This method's specimens could be cured lectic acid on the surface of samples cube specimens in lectic acid. The tested surface should be formed or finished and positioned at the contact of cutter on the plane. For the highly resistant concrete, there will be required an additional abrasion test. The test shall involve minimum two minutes and conducted on three separated areas of each representative concrete's surface. the test result will be able to describe more comprehensive as the following chart shown;

\subsubsection{Moh's scale Test}

The material's resistance of being scratched is defined as 'hardness'. The test is proceeded by placing a sharp point of one specimen on another unmarked surface specimen then attempting to create a scratch on it. The test will compare the resistance of a mineral being scratched with ten mineral references. It is known as Moh's Harness Scale as illustrated on Figure 4. Mohs Scale, from 1 (softest) to 10 (hardest) based on mineral type $1=$ Talc 2 = gypsum $3=$ Calcite $4=$ Fluorite $5=$ Apatite $6=$ Feldspar $7=$ quartz $8=$ Topaz $9=$ Corundum

10FA

$3,600 \mathrm{cc} . \quad 3,600 \mathrm{cc} . \quad 3,950 \mathrm{cc}$.
$35 \mathrm{~kg}(10 \%)$
fly ash
Figure 4. Moh's scale (Test Kit)

\section{Results and discussions}

The use of Pozzolans is not only help in strengthen and sealing the concrete, but also have more benefit in other features when this raw material is added or mixed with other materials. These are the benefit when applying with fly ash (FA) and silica fume (SF) in order to increase density and long-term pozzolanic action. This process can be ties up free lime, show fewer bleed channels and decreases permeability in the result. Moreover, Pozzolans can be combined with free lime to increase structural strength over time. [7] However, Actual water demand of Conventional concrete and 8FA22FA was highest content. While the actual water content of 30FA samples was equal. 30FA and 8SF22FA samples gained the similar initial slump at $22-21 \mathrm{~cm}$. Figure 5 and 6. Shows all cement samples had no adverse effects on slump loss properties and setting times of 8SF22FA were shortest. While the setting times of other samples were similar. (56 hrs.). Figure 7. shows all age, focusing at the 28-day compressive strength (the critical value), 8SF22FA gains the highest compressive strength when compare with 30FA, while Conventional concrete gains developed the lowest compressive strength at all ages. 


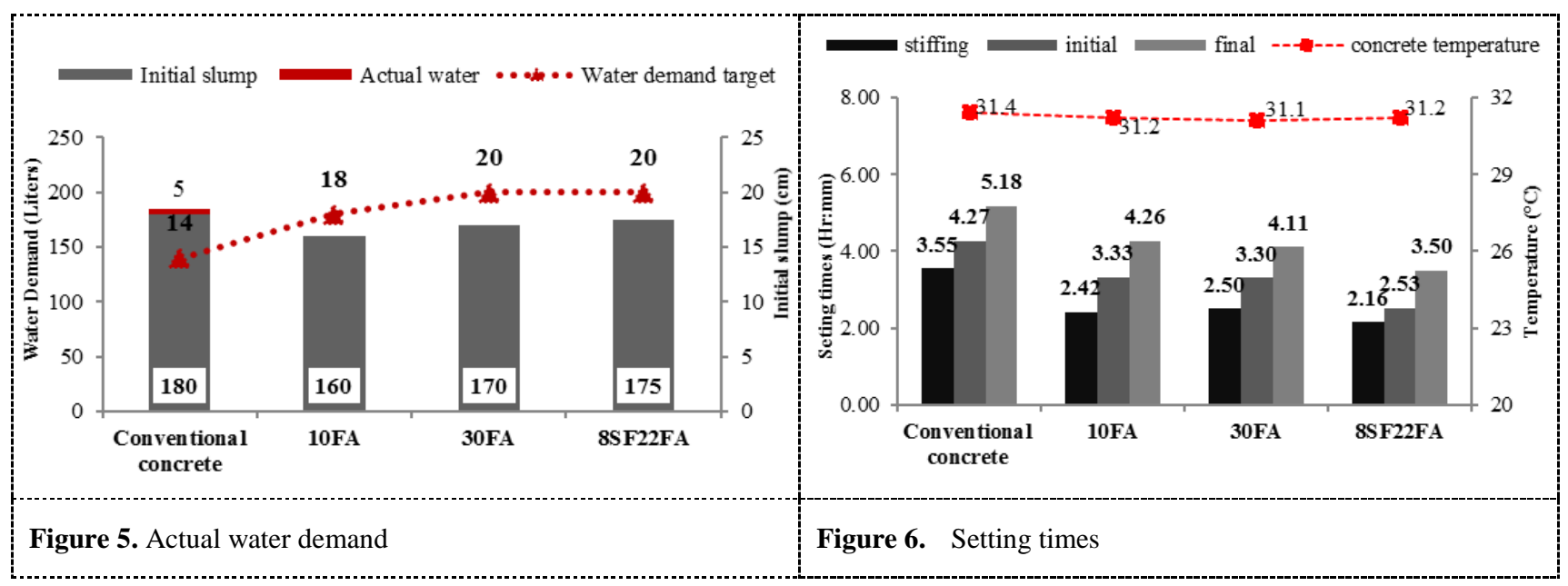

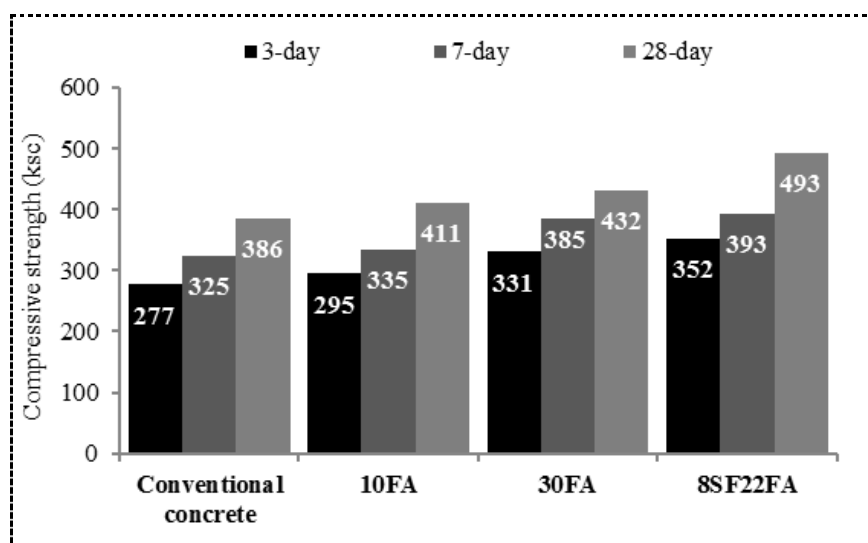

Figure 7. Compressive strength

The results for the ASTM C944 abrasion testing (single load) are presented in Figure 8 the average weight loss (grams) per abrading of 8SF22FA samples has the best result (average $1.9 \mathrm{~g}$ in 56 days) while the samples of Conventional concrete and with various \% replacement of Pozzolan material are worth 56-Day weight loss of all cement. Figure 9-12. The results for the Moh's scale testing are presented at 28 days. 8SF22FA gains the highest hardness around 8-9 when compare with other samples. No.8 (Topaz) is silicate mineral created from combination of aluminium and fluorine. No.9 (Corundum) is crystalline from of aluminium oxide and one of the basic rock-forming mineral.

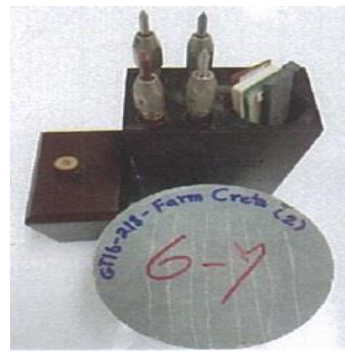

Figure 9. OPC 100\%

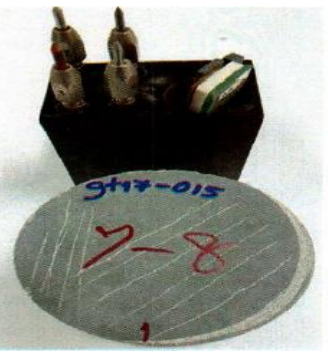

Figure 10. 10FA
Figure 8. ASTM C944 abrasion testing

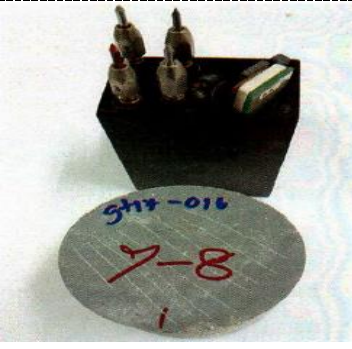

Figure 11. 25FA

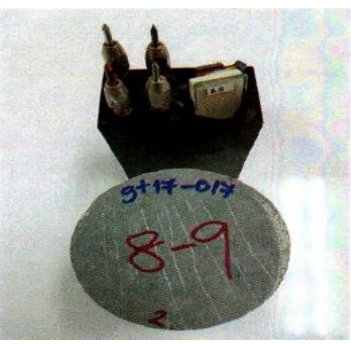

Figure 12. 8SF22FA

\section{Conclusions and recommendations}

Portland cement is the most useful ingredient and popular of concrete. Eventually, Portland cement concrete usually does not have good properties to acids. However, some weak acids can be tolerated as in Figure 5. 8SF22FA is a solution developed for highly aggressive agricultural environments, especially piglet farms compared to standard concrete and fly ash- concrete (10FA and 25FA). The 8SF22FA samples can offers a higher acid and abrasion resistance, better workability denser concrete structure and higher final strength. Lactic acid derived from feed that can react with free lime on the concrete and produce exceedingly soluble calcium salts may cause an extremely aggressive impact on the floor. [4] When the salt is leached, the concrete porosity will be raised in 
contrast to $\mathrm{pH}$ in the pores, which will be dropped. Therefore, the durable concrete mix provided the better solution for swine farm surface spalling. Increase volume of fly ash and silica fume can increase resistance of concrete from corrosion due to acid, significantly increase compressive strength at all ages, and increase abrasion resistance (ASTM C944). It is important and required to balance the strength and workability on the concrete work and slippery resistance. In the future, the investigation of the chemical and physical environment will be more significant and intensive in the most exposed areas of the farm buildings. [1] This knowledge can be applied and useful as a tool for material and components selecting with sustained durability.

\section{Acknowledgments}

These articles, Part I Feasibilities to Develop Concrete Floor of Swine Farm in Thailand, Part II Trial to Determine Durability and Serviceability for swine farm in Thailand. The author would like to express her very great appreciation to Asst.Prof.Dr. Chalida U-tapao for valuable and constructive suggestions also like to thank my parents and friends for providing unfailing support and continuous encouragement and through the process of researching and writing this thesis. This accomplishment would not have been possible without them. Thank you.

\section{Reference lists}

1. N. De Belie, M. Debruyckere, D. Van Nieuwenburgs and B. De Blaeres 1997 Attack of concrete floors in pig houses by feed acids: Influence of fly ash addition and cement-bound surface layers. J. Agric. Engng Res. 68 pp 101-08

2. Shelton, David P. and Harper and James M 1982 G82-623 An overview of concrete as a building material. Historical Materials from University of Nebraska-Lincoln Extension. 603., Issued December 1982 (12,000 printed)

3. Makanjuola Oki, Paul A L Anawe. 2015 A Review of Corrosion in Agricultural Industries. J. Phys Sci Inter 5(4): 216-222, Article no.PSIJ.2015.022 ISSN: 23480130

4. B. Svennerstedt Durability of building materials and components in agricultural environment. J. Agric. Engng Res. 75, Issue 3, March 2000, p. 225-241

5. Kramer, W. A. \& Braam and C. R. 1997 Deterioration of concrete exposed to lactic and acetic acid. Proceedings of the International Symposium on Concrete for a Susttiable Agriculture. 2 1-24 May 1997. S tavanger

6. Tikalsky PJ, Carrasquillo PM, Carrasquillo RL 1988 Strength and durability considerations affecting mix proportioning of concrete containing fly ash. ACI Mater J. 85(6) pp 505-11

7. Livestock statistics Agricultural Statistics of Thailand., 2015. Department of Livestock Development (DLD)., http://www.oae.go.th/main.php?filename=index__E $\mathrm{N}$ 